\title{
Does chemotherapy-induced neutropaenia result in a postponement of adjuvant or neoadjuvant regimens in breast cancer patients? Results of a retrospective analysis
}

\author{
M Debled",', N Houédé', N Madranges', C Donamaria ${ }^{2}$, A Floquet', M Durand' and Louis Mauriac' \\ 'Department of Medical Oncology, Institut Bergonié, Bordeaux, France; '2Department of Pharmacy, Institut Bergonié, Bordeaux, France
}

\begin{abstract}
In 2005, 224 patients received adjuvant/neoadjuvant chemotherapy for breast cancer in a single institution according to daily practices. Regimens consisted of epirubicin-based chemotherapy (FECI00, four or six cycles), or three cycles of FECI 00 followed by three cycles of docetaxel. An absolute blood count was carried out every 3 weeks, I - 3 days before planned chemotherapy cycle. Overall, 1238 cycles were delivered. An absolute neutrophil count (ANC) $<1.5 \times 10^{9} \mathrm{I}^{-1}$ before planned chemotherapy was found in 17 I cycles. Of these, I 30 cycles (76\%) were delivered as planned regardless of whether ANC levels recovered, and 4 I (24\%) were delayed. None of these patients developed a febrile neutropaenia. Haematopoietic support (granulocyte colony-stimulating factor (G-CSF)) was required in 12 cycles. We found that the majority of patients with an ANC $<1.5 \times\left. 10^{9}\right|^{-1}$ before planned chemotherapy received planned doses, without complications and need for G-CSF.
\end{abstract}

British Journal of Cancer (2007) 97, I642- |647. doi:I0.I038/sj.bjc.6604094 www.bjcancer.com

Published online 13 November 2007

(c) 2007 Cancer Research UK

Keywords: breast; chemotherapy; adjuvant; neutropaenia; dose intensity

The adjuvant treatment of breast cancer has evolved during the last 30 years. In the middle of the 1970s, Bonadonna et al (1995) pioneered the use of adjuvant chemotherapy by establishing the contribution of the CMF regimen (cyclophosphamide, methotrexate, and fluorouracil) to improvements in disease-free (DFS) and overall survival (OS). Successive overviews of the Early Breast Cancer Trialists' Collaborative Group (EBCTCG) (2005) have highlighted several trends, which have been reinforced over time: polychemotherapy is superior to monochemotherapy, anthracycline-based chemotherapy is superior to CMF, and the relative benefit of chemotherapy is independent of menopausal status and axillary lymph nodes involvement. Consequently, the anthracyclines are considered pivotal for adjuvant chemotherapy. Although no benefit of an increase in cyclophosphamide doses has been found (Smith et al, 2003), it has been shown that doxorubicin was more effective when used at a dose higher than $30 \mathrm{mg} \mathrm{m}^{-2}$ (Budman et al, 1998), and that an increase in epirubicin dose intensity significantly improved DFS and OS (Bonneterre et al, 2005). Therefore, anthracycline doses were gradually increased, especially for the treatment of node-positive breast cancer. Presently, the use of anthracycline-based regimens extends to high-risk, node-negative patients. Taxanes (paclitaxel and docetaxel) were introduced in the 1990s, and their role in the treatment of node-positive early breast cancer has been widely

*Correspondence: Dr M Debled, Département d'Oncologie Médicale, Institut Bergonié, 229 cours de l'Argonne, Bordeaux 33000, France; E-mail: debled@bergonie.org

Received 25 July 2007; revised 14 October 2007; accepted 17 October 2007; published online 13 November 2007 investigated. To date, major randomised trials have shown a significant improvement in DFS (Citron et al, 2003; Henderson et al, 2003; Mamounas et al, 2005; Martin et al, 2005; Roche et al, 2006) and OS (Citron et al, 2003; Henderson et al, 2003; Martin et al, 2005; Roche et al, 2006), when a taxane is added to an anthracycline in sequential, concomitant, or dose-dense regimens.

Both the increase in anthracycline doses and introduction of taxanes have increased the incidence of myelotoxicity, resulting in a higher incidence of neutropaenia, and then an increased risk of febrile neutropaenia and life-threatening infections. According to the rules established by successive randomised trials, it is a current practice to postpone the next cycle for a week and/or to use lower drug doses below an accepted neutrophil count of $1.5 \times 10^{9} 1^{-1}$. This is detrimental to maintaining the dose intensity, and consequently, the efficacy of planned regimens (Weiss et al, 1987; Wood et al, 1994; Bonadonna et al, 1995; Budman et al, 1998; Chirivella et al, 2006). According to the criteria defined by Bonadonna et al (1995), it is assumed that chemotherapy dose intensity below $85 \%$ of the planned dose significantly decreases the treatment efficacy. To counterbalance the consequences of a low neutrophil count, the use of granulocyte colony-stimulating factors (G-CSFs) has been extended, limiting the risk of infection and maintaining the chemotherapy dose intensity if its reduction may compromise efficacy (Smith et al, 2006).

However, a systematic postponement of chemotherapy of 1 week when the neutrophil count is below $1.5 \times 10^{9} 1^{-1}$, or the use of G-CSF are often practised in clinical trials, they are not always consistent with community practices. Thereby, we conducted a retrospective analysis of non-selected breast cancer patients receiving adjuvant or neoadjuvant $100-\mathrm{mg} \mathrm{m}^{-2}$ epirubicin-based 
regimens with or without sequential docetaxel. The purpose of this analysis was to evaluate the feasibility of those regimens in daily practices, and the real incidence of treatment delays and use of haematopoietic support.

\section{PATIENTS AND METHODS}

\section{Study population and treatment regimens}

All non-metastatic breast cancer patients who had received adjuvant or neoadjuvant chemotherapy outside clinical trials in 2005 were reviewed in our institution (Institut Bergonié, Bordeaux, France). The data reviewed and recorded in the hospital file were absolute neutrophil count (ANC) measured at baseline, before next chemotherapy cycle and subsequently in case of cycle delay, date of chemotherapy administration and dose, prescription of G-CSF, and toxicities occurring between cycles. The only exclusion criterion was patients treated in neoadjuvant/adjuvant clinical trials.

Planned treatment regimens consisted of FEC100 (fluorouracil $500 \mathrm{mg} \mathrm{m}^{-2}$, epirubicin $100 \mathrm{mg} \mathrm{m}^{-2}$, cyclophosphamide $500 \mathrm{mg} \mathrm{m}^{-2}$ day 1 , every 21 days) for four or six cycles according to axillary lymph nodes involvement, or three cycles of FEC100 followed by three cycles of docetaxel (D) $100 \mathrm{mg} \mathrm{m}^{-2}$ (day 1, every 21 days) (Roche et al, 2006). In case of overexpression and/or amplification of HER-2, patients received trastuzumab started concurrently with docetaxel (D). Adjuvant endocrine therapy and radiotherapy were started at the end of chemotherapy when indicated.

\section{Data analysis}

According to the standard practices of our institution, a blood count is carried out (outside the hospital) the day before the planned chemotherapy infusion (contingently Friday or Saturday when treatment was planned on Monday). The decision to deliver chemotherapy, to control ANC at the time of patient's hospital entry, or to postpone the next chemotherapy cycle depends on ANC, perceived risk of infectious events, and oncologist experience. Qualitative data were presented as a percentage, and ANC quantitative data were described using mean, median, s.d., and range. The relative dose intensity (RDI) was calculated based on the ratio of the drug doses actually delivered in the originally expected time over the expected dose in the expected time (Ferreira Filho et al, 2002).

\section{RESULTS}

\section{Patient characteristics and treatment protocols}

During the year 2005, 224 non-metastatic breast cancer patients were treated in this setting. The median age was 49 years (range: 26-72 years) with 37 patients (16.5\%) older than 60 years, and three $(1.3 \%)$ older than 70 years. Four chemotherapy regimens were delivered: (1) four cycles of FEC100; (2) six cycles of FEC100; (3) three cycles of FEC100 followed by three cycles of docetaxel (D); (4) three cycles of FEC100 followed by three cycles of docetaxel (D) plus trastuzumab. Noteworthy, 90\% of FEC100-D regimens were initiated after March 2005 consequently to the results of PACS 01 trial (Roche et al, 2006). The distribution of each regimen is summarised in Table 1 . Sixty-two patients $(27.7 \%)$ received chemotherapy in neoadjuvant setting.

Planned doses of chemotherapy were well respected (Table 2). The treatment planned was changed for eight patients (3.6\%): six with FEC100-D regimen (severe cutaneous toxicity in three, patient's refusal in two, and hypersensitivity in one); and two with FEC100 because of pancytopaenia in one and digestive toxicity in the other. Forty-six cycles $(4.5 \%)$ were delayed for more
Table I Distribution of treatment protocols among the 224 selected breast cancer patients

\begin{tabular}{|c|c|c|c|c|}
\hline & 4 FECIOO & 6 FECIOO & 3 FECI00-3D & 3 FECI00-3D+T \\
\hline Patients, n (\%) & $54(24.1)$ & $59(26.3)$ & $94(42.0)$ & $17(7.6)$ \\
\hline \multicolumn{5}{|l|}{$\begin{array}{c}\text { Chemotherapy, } \\
n(\%)\end{array}$} \\
\hline Adjuvant & $53(98.1)$ & $37(62.7)$ & $63(67.0)$ & $9(52.9)$ \\
\hline Neoadjuvant & I (1.9) & $22(37.3)$ & $31(33.0)$ & $8(47.1)$ \\
\hline \multicolumn{5}{|l|}{ Age, years } \\
\hline Median (range) & $49(30-72)$ & $50(29-68)$ & $50(26-69)$ & $48(3 \mid-72)$ \\
\hline $\begin{array}{l}>60 \text { years, } \\
n(\%)\end{array}$ & $5(9.2)$ & $9(15.2)$ & $20(21.3)$ & $3(17.6)$ \\
\hline $\begin{array}{l}>70 \text { years, } \\
n(\%)\end{array}$ & I (I.8) & $0(0.0)$ & $0(0.0)$ & $2(11.8)$ \\
\hline
\end{tabular}

$\mathrm{D}=$ docetaxel $100 \mathrm{mg} \mathrm{m}^{-2}$ every 21 days; $\mathrm{FECl} 00=$ fluorouracil $500 \mathrm{mg} \mathrm{m}^{-2}$, epirubicin $100 \mathrm{mg} \mathrm{m}^{-2}$, cyclophosphamide $500 \mathrm{mg} \mathrm{m}^{-2}$ every 21 days; $T=$ trastuzumab.

Table 2 Relative dose intensity according to treatment protocol

\begin{tabular}{|c|c|c|c|}
\hline & 4 FECIOO & 6 FECI00 & 3 FECI00-3D $( \pm T)$ \\
\hline $\begin{array}{l}\text { Number of patients } \\
\text { RDI, median (range) } \\
\mathrm{RDI}>95 \%, n(\%) \\
\mathrm{RDI}<85 \%, n(\%)\end{array}$ & $\begin{array}{c}54 \\
99 \%(75-10 \mid) \\
4 \mid(76) \\
4(7)\end{array}$ & $\begin{array}{c}59 \\
97 \%(76-102) \\
42(7 \mid) \\
4(7)\end{array}$ & $\begin{array}{c}11 \mid \\
99 \%(68-102) \\
89(80) \\
6(5)\end{array}$ \\
\hline
\end{tabular}

than 7 days in 35 patients (15.6\%). In half of the cases, this delay was the result of neutropaenia. A $20-25 \%$ dose reduction was applied in 19 cycles (1.9\%) and nine patients (4\%): five patients received FEC100-D, and four received FEC100 (Table 3).

\section{Absolute neutrophil count, cycle delay, and relative dose intensity}

An overall number of 1238 cycles have been administered. Among the 1007 cycles delivered between the second and the sixth courses, ANCs were available in 995 cases $(98.8 \%)$. The ANCs have been measured on day 21 in 510 cases $(51.3 \%)$, on day 20 in 136 cases $(13.7 \%)$, on day 19 in 41 cases $(4.1 \%)$, and on day 18 in 22 cases $(2.2 \%)$. In 220 cases $(22.1 \%)$, ANC was measured at the time of hospital entry for chemotherapy on day 22 or 23 . The ANC was measured on days $24-29$ in 76 cases $(7.6 \%)$ because of a cycle delay related to non-haematological toxicities or patient convenience. An ANC $<1.5 \times 10^{9} 1^{-1}$ was reported in 171 cases $(17.2 \%)$ secondary to 16 cases out of 220 having an ANC measured on day 22 or $23(7.2 \%), 89$ out of 510 ANC on day 21 (17.5\%), 44 out of 136 ANC on day $20(32.4 \%), 15$ out of 41 ANC on day $19(36.6 \%)$, and 7 out of 22 ANC on day $18(31.8 \%)$. This situation occurred in 169 cycles after FEC100 out of 791 (21.4\%), and in 2 out of 216 cycles $(0.9 \%)$ after docetaxel (D). Among cycles with ANC $<1.5 \times 10^{9} 1^{-1}$, three situations were possible (Figure 1). (1) The next chemotherapy cycle was delivered without postponement and no need for a new ANC in 69 cases (40.3\%): in seven cases $(10.1 \%)$ the ANC was below $1 \times 10^{9} 1^{-1}$, and in nine cases $(13 \%)$ the ANC has been measured 3 or 4 days before treatment. (2) A repeat of ANC was measured at the time of patient's hospital entry within 2 days in 70 cases $(40.9 \%)$. (3) Thirty-two cycles required a repeat of ANC more than 2 days after the first measurement. A new repeat was performed at a mean interval of 4.8 days (range: $3-8$ days) showing a neutrophil recovery in $100 \%$ of the cases and allowing chemotherapy administration. 


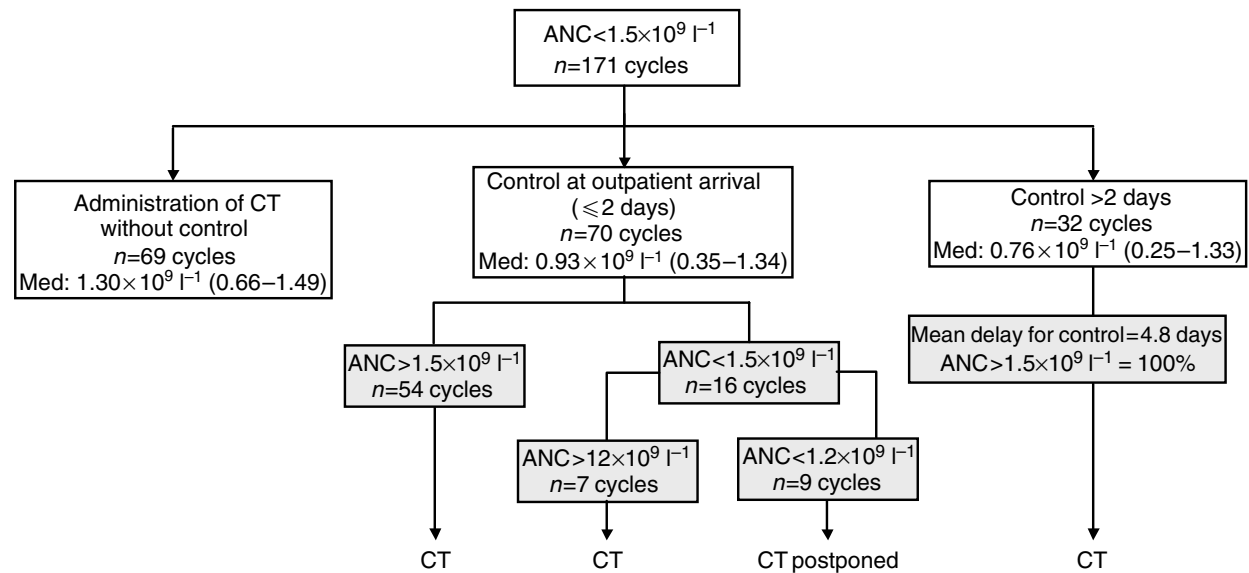

Figure I Flow chart of chemotherapy administration according to absolute neutrophil count below $1.5 \times 10^{9} \mathrm{I}^{-1}$. ANC, absolute neutrophil count; $\mathrm{CT}$, chemotherapy. Med: median ANC (min-max).

Table 3 Haematologic toxicities of treatment

4 FECI00 6 FECI00 3 FECI00-3D ( \pm T) Total

\begin{tabular}{|c|c|c|c|c|}
\hline Number of patients & 54 & 59 & | | | & 224 \\
\hline Patients with toxicity & 11 & 18 & 22 & 51 \\
\hline Hospitalisation $^{\text {a }}$ & I & 0 & 4 & 5 \\
\hline $\begin{array}{l}\text { Changes in treatment } \\
\text { plan }\end{array}$ & 1 & 1 & 6 & 8 \\
\hline Cycle delay $\geqslant 7$ days & 9 & 16 & 21 & 46 \\
\hline Dose reduction $\geqslant 15 \%$ & 0 & 4 & 5 & 9 \\
\hline G-CSF & 2 & 5 & I & 8 \\
\hline
\end{tabular}

$\mathrm{D}=$ docetaxel $100 \mathrm{mg} \mathrm{m}^{-2}$ every 21 days; $\mathrm{FEClO0}=$ fluorouracil $500 \mathrm{mg} \mathrm{m}^{-2}$ epirubicin $100 \mathrm{mg} \mathrm{m}^{-2}$, cyclophosphamide $500 \mathrm{mg} \mathrm{m}^{-2}$ every 21 days; G-CSF = granulocyte colony-stimulating factor; $T=$ trastuzumab. ${ }^{a}$ Febrile neutropaenia $(n=3)$, cutaneous toxicity $(n=1)$, and acute colitis $(n=1)$. ' Suppression of one cycle of FEC because of pancytopaenia $(n=1)$, suppression of one or two cycles of $D$ because of hypersensitivity $(n=1)$ or patient willingness $(n=2)$, replacement of one cycle of FEC by $D$ because of severe emesis $(n=1)$, replacement of one or two cycles of $D$ by FEC because of cutaneous toxicity $(n=3)$

Overall, 130 cycles (76\%) were delivered as planned with or without a repeat of ANC, and $41(24 \%)$ has to be delayed because of neutropaenia. In case of ANC $<1.5 \times 10^{9} 1^{-1}$, the subsequent blood counts showed that neutrophil recovery occurred in $75 \%$ of cases $(39 / 52)$ on day +1 , in $83 \%(15 / 18)$ on day +2 , and in $100 \%(32 / 32)$ from days +3 to +8 . When the repeat of ANC has been measured within $48 \mathrm{~h}$ following an ANC $<1.5 \times 10^{9} 1^{-1}$, the neutrophil recovery was $100 \%(n=37)$ if $\mathrm{ANC}>1 \times 10^{9} \mathrm{l}^{-1}$, and $70 \%(n=33)$ if ANC $<1 \times 10^{9} 1^{-1}$.

The RDI of each protocol is described in Table 2. An RDI higher than $95 \%$ was reached in 172 patients $(76.8 \%)$, whereas 14 patients $(6.2 \%)$ have received lower than $85 \%$ of the planned dose. The decrease in RDI was the result of haematologic toxicity or infectious complications in one-third of cases. Other reasons were cycle delays related to patients or hospital convenience.

\section{Safety profile and haematopoietic support}

Among the 76 chemotherapy cycles delivered in spite of an ANC $<$ 1.5. $\times 10^{9} 1^{-1}$, no case of infections were reported. On the other hand, 14 cases of febrile neutropaenia were reported, of which 10 occurred consequently to the first cycle, and four between the second and the sixth cycles with an ANC at the initiation of chemotherapy of $3.51,3.53,6.09$, and $7.83 \times 10^{9} 1^{-1}$, respectively. A secondary prophylaxis with G-CSF was required in eight patients (3.6\%) because of febrile neutropaenia in three cases and prevention of neutropaenia-related cycle delay in five cases. The main toxicities of treatment are presented in Table 3. Besides, seven patients $(3.1 \%)$ experienced a severe cutaneous toxicity related to docetaxel. No toxic death or persistent toxicity was registered.

\section{DISCUSSION}

Over time, growing evidence has emerged that chemotherapy RDI is a key principle of adjuvant chemotherapy efficacy. The long-term follow-up results of the CMF trial, conducted by Bonadonna et al (1995), showed that the 20 -year DFS of patients was $52 \%$ when they had received at least $85 \%$ of the planned dose versus $27 \%$ if the dose was below this rate. This has been confirmed by other retrospective studies using either CMF (Mayers et al, 2001) or anthracyclinebased regimens (Chirivella et al, 2006). Moreover, numerous retrospective studies suggested that early breast cancer patients who experienced the greater myelosuppression related to adjuvant chemotherapy have a trend towards a better outcome (Saarto et al, 1997; Colleoni et al, 1998; Poikonen et al, 1999; Mayers et al, 2001; Cameron et al, 2003). Additionally, prospective studies demonstrated that an increase in chemotherapy RDI resulted in an improvement of DFS and OS (Budman et al, 1998; Citron et al, 2003; Bonneterre et al, 2005). In spite of these clear data, several retrospective analyses evaluating adjuvant chemotherapy RDI in daily practices have shown a significant decrease in RDI, irrespective of country and chemotherapy regimen (Link et al, 2001; Morrow et al, 2002; Ottevanger et al, 2002; Leonard et al, 2003; Lyman et al, 2003; Schaapveld et al, 2004; Chirivella et al, 2006; Shayne et al, 2006). Among these analyses, $20-30 \%$ of patients received less than $85 \%$ of pre-planned chemotherapy schedule. However, the percentage of patients receiving $<85 \%$ of the dose has been gradually reduced. Indeed, there was a $26 \%$ decrease in dose reduction $<85 \%$ across successive analyses of a same report (Lyman et al, 2003; Shayne et al, 2006). One could argue that physicians and quality of care control have assumed that the criterion of Bonadonna et al (1995) with a cutoff value of $85 \%$ as efficacy predictor was major for the management of early breast cancer patients (Budman et al, 1998; Mayers et al, 2001; Morrow et al, 2002; Ottevanger et al, 2002; Shayne et al, 2006).

For the first use of FEC100 regimen in the French Adjuvant Study Group (FASG) 05 trial, conducted between 1990 and 1993, no prophylactic use of G-CSF was permitted, and an AN$\mathrm{C}<2 \times 10^{9} \mathrm{l}^{-1}$ led to a treatment interruption of at least 1 week (Bonneterre et al, 2005). Thereby, among the 268 patients who received the FEC100 regimen, the mean RDI was $86.1 \%$, and seven cases $(2.6 \%)$ of febrile neutropaenia occurred. More recently, in the PACS 01 trial initiated in 1997 and comparing 6 FEC100 to 3 FEC100-3D, the mandatory ANC for a subsequent cycle delivery 
was lowered to $1.5 \times 10^{9} \mathrm{l}^{-1}$, whereas an $\mathrm{ANC}<1.5 \times 10^{9} \mathrm{l}^{-1}$ required the use of G-CSF for all subsequent cycles (Roche et al, 2006). In this trial, the median RDI was 98 and $99 \%$, respectively, whereas G-CSF was prescribed in $27 \%$ of the patients receiving FEC100 compared with $22 \%$ of those receiving docetaxel. Noteworthy, only 8.4 and $11.2 \%$ of patients, respectively, developed a febrile neutropaenia, showing that the prescription of G-CSF aimed predominantly to facilitate neutrophil recovery and to maintain RDI rather than to prevent secondary infections. The comparison between these two randomised trials highlights that changes in treatment modalities lead to a $12 \%$ increase of RDI, whereas the use of G-CSF is multiplied by 35 (Bonneterre et al, 2005; Roche et al, 2006).

One of the major reasons identified for a reduction in chemotherapy doses was neutropaenia (Silber et al, 1998; Link et al, 2001). Indeed, chemo-induced neutropaenia are often controlled by dose reductions, or cycle delays, which may compromise the disease outcome. The most frequently used option is the use of G-CSF, according to the International Oncology guidelines, which consider that a G-CSF prophylaxis can be used to maintain adequate dose intensity for disease outcome (Greil and Jost, 2005; Aapro et al, 2006; Smith et al, 2006; Lyman and Kleiner, 2007). However, the guidelines are a little variable on their indications for use of haematopoietic support. For instance, Smith et al (2006) did not recommend use maintaining dose intensity for adjuvant breast cancer chemotherapy, as they considered that there is no evidence that a slight decrease in dose or a slight prolongation of dose interval worsens outcome. Moreover, an extension in the use of G-CSF may be counterbalanced by long-term side effects. First, some data suggested that G-CSF might worsen anaemia in patients receiving adjuvant chemotherapy (Papaldo et al, 2006). Of major concerns, an increased risk of secondary acute myeloblastic leukaemia (AML) and myelodysplastic syndrome (MDS) has been recently reported (Smith et al, 2003; Praga et al, 2005; Veyret et al, 2006; Hershman et al, 2007; Le Deley et al, 2007). The relationship between AML/MDS because of haematopoietic support must be cautiously interpreted because of the accumulation of confusing factors. Meanwhile, G-CSF use should not be assumed to be risk free. The G-CSF could be more cost-effectively and cautiously applied if targeted to patients with identified risk factors of febrile neutropaenia instead of severe neutropaenia (Borg et al, 2004). Another option could be a prophylactic use of antibiotics (Schröder et al, 1999). However, it remains controversial as recently illustrated by comments following publication of a randomised study on this topic (Cullen et al, 2005, and correspondence).

Another means to maintain RDI of adjuvant chemotherapy may be to lower ANC threshold for administration of chemotherapy. Our experience showed that no infectious complications occurred among 76 patients who received a full-dose schedule despite an ANC $<1.5 \times 10^{9} 1^{-1}$. This observation is in agreement with data reported in the literature showing that an ANC $<1.5 \times 10^{9} 1^{-1}$ at the onset of chemotherapy was not convincingly associated with an increased risk of febrile neutropaenia (Greil and Jost, 2005). Previously, the National Surgical Adjuvant Breast and Bowel Project B-15 and B-16 trials showed that the reintroduction of chemotherapy with ANC ranging between 1.0 and $1.5 \times 10^{9} 1^{-1}$ was possible (Fisher et al, 1990a,b). In a recent retrospective study involving Hodgkin's lymphoma patients, the ABVD (adriamycin, bleomycin, vinblastine, and dacarbazine) administration irrespective of granulocyte counts allowed the treatment to be given at full dose without delays or significant number of infective episodes (Boleti and Mead, 2007). Authors concluded that they found no increased risk of severe infections despite the vast majority of patients experiencing at least one episode of grades 3-4 neutropaenia, of which one-third had at least one episode of grade 4 toxicity. In the present analysis, neutrophil recovery occurred always around the twenty-first day, and did not justify a postponement of 8 days. We could conclude that the 7-day median cycle delay is a consequence of daily practices based on convenient factors. The reduction of the delay by re-evaluating blood counts after 2-3 days would probably improve RDI.

However, our results must be cautiously considered. First, in our standard practices, an adjuvant chemotherapy was not prescribed to patients older than 70 years outside clinical trials, taking into account that no significant benefits were found in EBCTCG overviews (Early Breast Cancer Trialists' Collaborative Group (EBCTCG), 2005). This standard could be debatable according to recent results of randomised trials showing a significant reduction in breast cancer recurrence and mortality with adjuvant chemotherapy for elderly patients (Fargeot et al, 2004; Muss et al, 2005). On the other hand, the advanced age has been found to be an independent prognostic factor of decrease in RDI (Bonadonna et al, 1995; Crivellari et al, 2000; Lyman et al, 2003; Shayne et al, 2006), and to be associated with a higher rate of neutropaenic complications (Crivellari et al, 2000; Dees et al, 2000; Muss et al, 2007), of which clinical consequences were more severe (Balducci and Yates, 2000). Second, the 3 FEC100-3D regimen may be a favourable schedule for re-treatment with a low ANC as docetaxel (D) induces deep but short neutropaenia always corrected on day 22. A re-treatment at ANC of $1 \times 10^{9} 1^{-1}$ or less may not be applied with other adjuvant regimens that affect more strongly bone marrow. It has been found that doxorubicin-CMF regimen necessitated further delays subsequently to the first episode in the absence of dose reduction, dose delay, or G-CSF administration (Rivera et al, 2003). Across classical chemotherapy regimens used in clinical practice (Canadian CEF, oral or intravenous $\mathrm{CMF}, \mathrm{AC}), 42 \%$ of patients experienced at least one neutropaenic event, and $72 \%$ of them developed additional events in subsequent cycles (Chang, 2000). When docetaxel was used concurrently with fluorouracil and cyclophosphamide (TAC) plus systematic antibiotic prophylaxis, the incidence of grades 3-4 neutropaenia on day 21 was $65 \%$, with $24 \%$ of febrile neutropaenia requiring subsequent use of G-CSF (Martin et al, 2005).

In conclusion, this analysis confirms that four-six cycles of FEC100 and three FEC100-3D regimens are feasible in the general population without severe toxicity. Both regimens provide a high RDI, a worthwhile goal for patients receiving adjuvant chemotherapy for breast cancer. This high RDI was achieved without need for G-CSF, and infectious events were rare in spite of the absence of prophylactic antibiotherapy. Using these regimens, the ANC recovery was always observed after about 3 weeks, without any risk of long-lasting neutropaenia. In our opinion, there is no justification for the historical threshold ANC of $1.5 \times 10^{9} 1^{-1}$ for administration of adjuvant chemotherapy.

\section{ACKNOWLEDGEMENTS}

This work was supported by grants from Sanofi-aventis, France. Isabelle Chapelle-Marcillac provided editorial assistance in the preparation of the manuscript.

We thank also Carine Genty for her excellent medical assistance at the 1-day hospital allowing this retrospective analysis to be performed.

\section{REFERENCES}

Aapro MS, Cameron DA, Pettengell R, Bohlius J, Crawford J, Ellis M, Kearney N, Lyman GH, Tjan-Heijnen VC, Walewski J, Weber DC,
Zielinski C, European Organisation for Research and Treatment of Cancer (EORTC) Granulocyte Colony-Stimulating Factor (G-CSF) 
Guidelines Working Party (2006) EORTC guidelines for the use of granulocyte-colony stimulating factor to reduce the incidence of chemotherapy-induced febrile neutropenia in adult patients with lymphomas and solid tumours. Eur J Cancer 42: 2433-2453

Balducci L, Yates J (2000) General guidelines for the management of older patients with cancer. Oncology (Williston Park) 14: $221-227$

Boleti E, Mead GM (2007) ABVD for Hodgkin's lymphoma: full-dose chemotherapy without dose reductions or growth factors. Ann Oncol 18: $376-380$

Bonadonna G, Valagussa P, Moliterni A, Zambetti M, Brambilla C (1995) Adjuvant cyclophosphamide, methotrexate, and fluorouracil in nodepositive breast cancer: the results of 20 years of follow-up. $N$ Engl J Med 332: $901-906$

Bonneterre J, Roche H, Kerbrat P, Bremond A, Fumoleau P, Namer M, Goudier MJ, Schraub S, Fargeot P, Chapelle-Marcillac I (2005) Epirubicin increases long-term survival in adjuvant chemotherapy of patients with poor-prognosis, node-positive, early breast cancer: 10-year follow-up results of the French Adjuvant Study Group 05 randomized trial. J Clin Oncol 23: $2686-2693$

Borg C, Ray-Coquard I, Philip I, Clapisson G, Bendriss-Vermare N, Menetrier-Caux C, Sebban C, Biron P, Blay JY (2004) CD4 lymphopenia as a risk factor for febrile neutropenia and early death after cytotoxic chemotherapy in adult patients with cancer. Cancer 101: 2675-2680

Budman DR, Berry DA, Cirrincione CT, Henderson IC, Wood WC, Weiss RB, Ferree CR, Muss HB, Green MR, Norton L, Frei E (1998) Dose and dose intensity as determinants of outcome in the adjuvant treatment of breast cancer. The Cancer and Leukemia Group B. J Natl Cancer Inst 90: $1205-1211$

Cameron DA, Massie C, Kerr G, Leonard RC (2003) Moderate neutropenia with adjuvant CMF confers improved survival in early breast cancer. $\mathrm{Br} \mathrm{J}$ Cancer 89: $1837-1842$

Chang J (2000) Chemotherapy dose reduction and delay in clinical practice. Evaluating the risk to patient outcome in adjuvant chemotherapy for breast cancer. Eur J Cancer 36(Suppl 1): S11-S14

Chirivella I, Bermejo B, Insa A, Perez-Fidalgo A, Magro A, Rosello S, Garcia-Garre E, Martin P, Bosch A, Lluch A (2006) Impact of chemotherapy dose-related factors on survival in breast cancer patients treated with adjuvant anthracycline-based chemotherapy. Proc Am Soc Clin Oncol in J Clin Oncol 24: 668 (abstract)

Citron ML, Berry DA, Cirrincione C, Hudis C, Winer EP, Gradishar WJ, Davidson NE, Martino S, Livingston R, Ingle JN, Perez EA, Carpenter J, Hurd D, Holland JF, Smith BL, Sartor CI, Leung EH, Abrams J, Schilsky RL, Muss HB, Norton L (2003) Randomized trial of dose-dense versus conventionally scheduled and sequential versus concurrent combination chemotherapy as postoperative adjuvant treatment of node-positive primary breast cancer: first report of Intergroup Trial C9741/Cancer and Leukemia Group B Trial 9741. J Clin Oncol 21: 1431 - 1439

Colleoni M, Price K, Castiglione-Gertsch M, Goldhirsch A, Coates A, Lindtner J, Collins J, Gelber RD, Thürlimann B, Rudenstam CM (1998) Dose-response effect of adjuvant cyclophosphamide, methotrexate, 5fluorouracil (CMF) in node-positive breast cancer. International Breast Cancer Study Group. Eur J Cancer 34: 1693-1700

Crivellari D, Bonetti M, Castiglione-Gertsch M, Gelber RD, Rudenstam CM, Thürlimann B, Price KN, Coates AS, Hürny C, Bernhard J, Lindtner J, Collins J, Senn HJ, Cavalli F, Forbes J, Gudgeon A, Simoncini E, Cortes-Funes H, Veronesi A, Fey M, Goldhirsch A (2000) Burdens and benefits of adjuvant cyclophosphamide, methotrexate, and fluorouracil and tamoxifen for elderly patients with breast cancer: the International Breast Cancer Study Group Trial VII. J Clin Oncol 18: $1412-1422$

Cullen M, Steven N, Billingham L, Gaunt C, Hastings M, Simmonds P, Stuart N, Rea D, Bower M, Fernando I, Huddart R, Gollins S, Stanley A, Simple Investigation in Neutropenic Individuals of the Frequency of Infection after Chemotherapy $+/-$ Antibiotic in a Number of Tumours (SIGNIFICANT) Trial Group (2005) Antibacterial prophylaxis after chemotherapy for solid tumors and lymphomas. $N$ Engl $J$ Med 353: $988-998$

Dees EC, O'Reilly S, Goodman SN, Sartorius S, Levine MA, Jones RJ, Grochow LB, Donehower RC, Fetting JH (2000) A prospective pharmacologic evaluation of age-related toxicity of adjuvant chemotherapy in women with breast cancer. Cancer Invest 18: 521-529

Early Breast Cancer Trialists' Collaborative Group (EBCTCG) (2005) Effects of chemotherapy and hormonal therapy for early breast cancer on recurrence and 15-year survival: an overview of the randomised trials. Lancet 365: $1687-1717$
Fargeot P, Bonneterre J, Roché H, Lortholary A, Campone M, Van Praagh I, Monnier A, Namer M, Schraub S, Barats JC, Guastalla JP, Goudier MJ, Chapelle-Marcillac I (2004) Disease-free survival advantage of weekly epirubicin plus tamoxifen versus tamoxifen alone as adjuvant treatment of operable, node-positive, elderly breast cancer patients: 6-year followup results of the French adjuvant study group 08 trial. J Clin Oncol 22: $4622-4630$

Ferreira Filho AF, Di Leo A, Paesmans M, Beauduin M, Vindevoghel A, Michel J, Focan C, Awada A, Cardoso F, Dolci S, Bartholomeus S, Piccart MJ (2002) The feasibility of classical cyclophosphamide, methotrexate, 5 fluorouracil (CMF) for pre- and post-menopausal node-positive breast cancer patients in a Belgian multicentric trial: a study of consistency in relative dose intensity (RDI) and cumulative doses across institutions. Ann Oncol 13: 416-421

Fisher B, Brown AM, Dimitrov NV, Poisson R, Redmond C, Margolese RG Bowman D, Wolmark N, Wickerham DL, Kardinal CG, Shibata H, Paterson AHG, Sutherland CM, Robert NJ, Ager PJ, Levy L, Wolter J, Wozniak T, Fisher ER, Deutsch M (1990a) Two months of doxorubicincyclophosphamide with and without interval reinduction therapy compared with 6 months of cyclophosphamide, methotrexate, and fluorouracil in positive-node breast cancer patients with tamoxifennonresponsive tumors: results from the National Surgical Adjuvant Breast and Bowel Project B-15. J Clin Oncol 8: 1483-1496

Fisher B, Redmond C, Legault-Poisson S, Dimitrov NV, Brown AM, Wickerham DL, Wolmark N, Margolese RG, Bowman D, Glass AG, Kardinal CG, Robidoux A, Jochimsen P, Cronin W, Deutsch M, Fisher ER, Myers DB, Hoehn JL (1990b) Postoperative chemotherapy and tamoxifen compared with tamoxifen alone in the treatment of positivenode breast cancer patients aged 50 years and older with tumors responsive to tamoxifen: results from the National Surgical Adjuvant Breast and Bowel Project B-16. J Clin Oncol 8: 1005-1018

Greil R, Jost LM (2005) ESMO recommendations for the application of hematopoietic growth factors. Ann Oncol 16(Suppl 1): i80 - i82

Henderson IC, Berry DA, Demetri GD, Cirrincione CT, Goldstein LJ, Martino S, Ingle JN, Cooper MR, Hayes DF, Tkaczuk KH, Fleming G, Holland JF, Duggan DB, Carpenter JT, Frei III E, Schilsky RL, Wood WC, Muss HB, Norton L (2003) Improved outcomes from adding sequential paclitaxel but not from escalating doxorubicin dose in an adjuvant chemotherapy regimen for patients with node-positive primary breast cancer. J Clin Oncol 21: 976-983

Hershman D, Neugut AI, Jacobson JS, Wang J, Tsai WY, McBride R, Bennett CL, Grann VR (2007) Acute myeloid leukemia or myelodysplastic syndrome following use of granulocyte colony-stimulating factors during breast cancer adjuvant chemotherapy. J Natl Cancer Invest 99: $196-205$

Le Deley MC, Suzan F, Cutuli B, Delaloge S, Shamsaldin A, Linassier C, Clisant S, de Vathaire F, Fenaux P, Hill C (2007) Anthracyclines, mitoxantrone, radiotherapy, and granulocyte colony-stimulating factor: risk factors for leukemia and myelodysplastic syndrome after breast cancer. J Clin Oncol 25: 292-300

Leonard RC, Miles D, Thomas R, Nussey F, UK Breast Cancer Neutropenia Audit Group (2003) Impact of neutropenia on delivering planned adjuvant chemotherapy: UK audit of primary breast cancer patients. $\mathrm{Br} \mathrm{J}$ Cancer 89: $2062-2068$

Link BK, Budd GT, Scott S, Dickman E, Paul D, Lawless G, Lee MW, Fridman M, Ford J, Carter WB, Oncology Practice Pattern Study Working Group (2001) Delivering adjuvant chemotherapy to women with early-stage breast carcinoma: current patterns of care. Cancer 92: $1354-1367$

Lyman GH, Dale DC, Crawford J (2003) Incidence and predictors of low dose-intensity in adjuvant breast cancer chemotherapy: a nationwide study of community practices. J Clin Oncol 21: 4524-4531

Lyman GH, Kleiner JM (2007) Summary and comparison of myeloid growth factor guidelines in patients receiving cancer chemotherapy. J Natl Compr Canc Netw 5: 217-228

Mamounas EP, Bryant J, Lembersky B, Fehrenbacher L, Sedlacek SM, Fisher B, Wickerham DL, Yothers G, Soran A, Wolmark N (2005) Paclitaxel after doxorubicin plus cyclophosphamide as adjuvant chemotherapy for node-positive breast cancer: results from NSABP B-28. J Clin Oncol 23: 3686-3696

Martin M, Pienkowski T, Mackey J, Pawlicki M, Guastalla JP, Weaver C, Tomiak E, Al-Tweigeri T, Chap L, Juhos E, Guevin R, Howell A, Fornander T, Hainsworth J, Coleman R, Vinholes J, Modiano M, Pinter T, Tang SC, Colwell B, Prady C, Provencher L, Walde D, RodriguezLescure A, Hugh J, Loret C, Rupin M, Blitz S, Jacobs P, Murawsky M, 
Riva A, Vogel C, Breast Cancer International Research Group 001 Investigators (2005) Adjuvant docetaxel for node-positive breast cancer. N Engl J Med 352: $2302-2313$

Mayers C, Panzarella T, Tannock IF (2001) Analysis of the prognostic effects of inclusion in a clinical trial and of myelosuppression on survival after adjuvant chemotherapy for breast carcinoma. Cancer 91: 22462257

Morrow T, Siegel M, Boone S, Lawless G, Carter W (2002) Chemotherapy dose intensity determination as a quality of care measure for managed care organizations in the treatment of early-stage breast cancer. Am J Med Qual 17: 218-224

Muss HB, Berry DA, Cirrincione C, Budman DR, Henderson IC, Citron ML, Norton L, Winer EP, Hudis CA, Cancer and Leukemia Group B Experience (2007) Toxicity of older and younger patients treated with adjuvant chemotherapy for node-positive breast cancer: the Cancer and Leukemia Group B Experience. J Clin Oncol 25: 3699-3704

Muss HB, Woolf S, Berry D, Cirrincione C, Weiss RB, Budman D, Wood WC, Henderson IC, Hudis C, Winer E, Cohen H, Wheeler J, Norton L, Cancer and Leukemia Group B (2005) Adjuvant chemotherapy in older and younger women with lymph node-positive breast cancer. JAMA 293: $1073-1081$

Ottevanger PB, De Mulder PH, Grol RP, Van Lier H, Beex LV (2002) Effects of quality of treatment on prognosis in primary breast cancer patients treated in daily practice. Anticancer Res 22: 459-465

Papaldo P, Ferretti G, Di Cosimo S, Giannarelli D, Marolla P, Lopez M, Cortesi E, Antimi M, Terzoli E, Carlini P, Vici P, Botti C, Di Lauro L, Naso G, Nisticò C, Mottolese M, Di Filippo F, Ruggeri EM, Ceribelli A, Cognetti F (2006) Does granulocyte colony-stimulating factor worsen anemia in early breast cancer patients treated with epirubicin and cyclophosphamide? J Clin Oncol 24: 3048-3055

Poikonen P, Saarto T, Lundin J, Joensuu H, Blomqvist C (1999) Leucocyte nadir as a marker for chemotherapy efficacy in node-positive breast cancer treated with adjuvant CMF. Br J Cancer 80: 1763-1766

Praga C, Bergh J, Bliss J Bonneterre J, Cesana B, Coombes RC, Fargeot P, Folin A, Fumoleau P, Giuliani R, Kerbrat P, Hery M, Nilsson J, Onida F, Piccart M, Shepherd L, Therasse P, Wils J, Rogers D (2005) Risk of acute myeloid leukemia and myelodysplastic syndrome in trials of adjuvant epirubicin for early breast cancer: correlation with doses of epirubicin and cyclophosphamide. J Clin Oncol 23: 4179-4191

Rivera E, Haim Erder M, Fridman M, Frye D, Hortobagyi GN (2003) Firstcycle absolute neutrophil count can be used to improve chemotherapydose delivery and reduce the risk of febrile neutropenia in patients receiving adjuvant therapy: a validation study. Breast Cancer Res 5: R114 - R120

Roche H, Fumoleau P, Spielmann M, Canon JL, Delozier T, Serin D, Symann M, Kerbrat P, Soulié P, Eichler F, Viens P, Monnier A,
Vindevoghel A, Campone M, Goudier MJ, Bonneterre J, Ferrero JM, Martin AL, Genève J, Asselain B (2006) Sequential adjuvant epirubicinbased and docetaxel chemotherapy for node-positive breast cancer patients: the FNCLCC PACS 01 Trial. J Clin Oncol 24: 5664-5671

Saarto T, Blomqvist C, Rissanen P, Auvinen A, Elomaa I (1997) Haematological toxicity: a marker of adjuvant chemotherapy efficacy in stage II and III breast cancer. Br J Cancer 75: 301-305

Schaapveld M, de Vries EG, van der Graaf WT, Otter R, Willemse PH (2004) Quality of adjuvant CMF chemotherapy for node-positive primary breast cancer: a population-based study. J Cancer Res Clin Oncol 130: 581-590

Schröder CP, de Vries EG, Mulder NH, Willemse PH, Sleijfer DT, Hospers GA, van der Graaf WT (1999) Prevention of febrile leucopenia after chemotherapy in high-risk breast cancer patients: no significant difference between granulocyte-colony stimulating growth factor or ciprofloxacin plus amphotericin B. J Antimicrob Chemother 43: 741-743

Shayne M, Crawford J, Dale DC, Culakova E, Lyman GH, for the ANC Study Group (2006) Predictors of reduced dose intensity in patients with earlystage breast cancer receiving adjuvant chemotherapy. Breast Cancer Res Treat 100: $255-262$

Silber JH, Fridman M, DiPaola RS, Erder MH, Pauly MV, Fox KR (1998) First-cycle blood counts and subsequent neutropenia, dose reduction, or delay in early-stage breast cancer therapy. J Clin Oncol 16: 2392-2400

Smith RE, Bryant J, DeCillis A, Anderson S, National Surgical Adjuvant Breast and Bowel Project Experience (2003) Acute myeloid leukemia and myelodysplastic syndrome after doxorubicin-cyclophosphamide adjuvant therapy for operable breast cancer: the National Surgical Adjuvant Breast and Bowel Project experience. J Clin Oncol 21: 1195-1204

Smith TJ, Khatcheressian J, Lyman GH, Ozer H, Armitage JO, Balducci L, Bennett CL, Cantor SB, Crawford J, Cross SJ, Demetri G, Desch CE, Pizzo PA, Schiffer CA, Schwartzberg L, Somerfield MR, Somlo G, Wade JC, Wade JL, Winn RJ, Wozniak AJ, Wolff AC (2006) 2006 update of recommendations for the use of white blood cell growth factors: an evidence-based clinical practice guideline. J Clin Oncol 24: 3187-3205

Veyret C, Levy C, Chollet P, Merrouche Y, Roche H, Kerbrat P, Fumoleau P, Fargeot P, Clavere P, Chevallier B (2006) Inflammatory breast cancer outcome with epirubicin-based induction and maintenance chemotherapy: ten-year results from the French Adjuvant Study Group GETIS 02 Trial. Cancer 107: 2535 - 2544

Weiss RB, Valagussa P, Moliterni A, Zambetti M, Buzzoni R, Bonadonna G (1987) Adjuvant chemotherapy after conservative surgery plus irradiation versus modified radical mastectomy. Analysis of drug dosing and toxicity. Am J Med 83: $455-463$

Wood WC, Budman DR, Korzun AH, Cooper MR, Younger J, Hart RD, Moore A, Ellerton JA, Norton L, Ferree CR et al (1994) Dose and dose intensity of adjuvant chemotherapy for stage II, node-positive breast carcinoma. N Engl J Med 330: 1253 - 1259 